\title{
The Impact of Environmental Standards as a Public Environmental Policy Tool on the Market Structure of Polluting Industries
}

\author{
Luciano Fanti ${ }^{1}$ and Domenico Buccella ${ }^{2 *}$ \\ ${ }^{1}$ Department of Economics and Management, University of Pisa, Italy \\ ${ }^{2}$ Department of Economics, Kozminski University in Warsaw, Poland \\ Email: buccella@kozminski.edu.pl
}

\begin{abstract}
This paper investigates the effects of public environmental policies on the market structure in a Cournot context. It is shown that when the Government fixes upper limits to emissions, higher environmental social concerns favour entry of a firm. On the other hand, the abatement technology may act as a barrier or an incentive to entry depending on the government's environmental sensitiveness; however, a more efficient technology tends to disfavour entry. In addition, if the size of the fixed costs is relatively high, the duopoly market structure will lead to social welfare level lower than in the presence of monopoly. On the other hand, an improvement of the efficiency of the abatement technology may, in the presence of a low social interest for controlling pollution, play the role of a barrier to entry. The empirical and policy implications of these results are discussed.
\end{abstract}

Keywords: Environmental policies; entry; cournot; endogenous market structure

\section{Introduction}

As known, the analysis of the determinants of the market structure is central to the Industrial Organization literature. The main question is what determines the number of firms in an industry and the possibility to remain dominant for a firm which is, for instance, monopolist in a market. In the words of Stiglitz (1986, ix) "while much of the earlier literature took the market structure (e.g. the number of firms) as given, the new theory of market structure begins by asking what determines the number of firms? What are the barriers to entry? .... The objective of this line of research is to identify exogenous variables - characteristics of technology (....) and of demand. These exogenous variables determine the market structure, which is thus viewed to be endogenous."

In the economic literature, McAfee et al. (2004) have identified eleven different definitions of barrier to entry. Loosely speaking, it is possible to categorise those barriers into two broad categories (Khemani and Shapiro, 1993; Church and Ware, 1999 p. 487): 1) innocent or structural barriers; and 2) strategic or behavioural barriers, which are endogenous and due to purposeful action by the incumbent. ${ }^{1}$ However, Church and Ware (1999) retain the term "barrier to entry" only for structural barriers which are exogenous and due to changes in technology, demand or government policies, that is, "a structural characteristic of a market that protects the market power of incumbents by making entry unprofitable."

This paper follows this line of research. More specifically, we study a market with pollution, and we identify whether and how two exogenous variables, which represent "innocent barriers", such as the governments' degree of environmental social concerns and a more or less efficient pollution abatement technology, play a role in shaping the market structure. Those issues represent a clear challenge for the firms' management as regards the corporate responses to the more and more frequent engagement of governments' in environmental policy.

${ }^{1}$ As regards the strategic barriers to entry, see the notable contributions of Spence (1977), Dixit (1980) and Shy (1995). 
As known, the literature on the environment so far analysed the environmental policy of the government under various points of view (see Requate, 2006, for a survey about the theoretical literature on environmental policy in the presence of imperfect competition). However, the received literature has not considered that there may be effects on the market structure through 1) the level of importance attributed to regulations to control pollution; and 2) the efficiency of the abatement technologies.

In fact, the literature about the use and the efficacy of environmental policies under a given specific market structure is vast. Only to mention a few, the main papers framed in a specific market structure are, e.g., Barnett (1980) for the monopoly case; Oates and Strassmann (1984) who extend Barnett's (1980) conclusions for other forms of market structures; Innes et al. (1991) for the case of a monopolist in a given commodity market, and other firms under perfect competition on different output markets, emitting the same pollutant; Requate (1993b) for the case of regulating several local monopolists. Levin (1985) is the first article analysing emission taxes for Cournot oligopoly; however, that author does not consider the damage from pollution. Besanko (1987) analyses different standards under Cournot competition. Subsequently Ebert (1992) takes also into account the damage from pollution for symmetric Cournot firms, and Simpson (1996) extends Ebert (1992) to the case of asymmetric duopoly firms. On the other hand, for a discussion under perfectly competitive markets, see Spulber (1985) and Baumol and Oates (1988). Nonetheless, less attention has been paid to the effects of environmental variables on the emergence of an endogenous market structure. The aim of this paper is precisely to fill this gap.

In this respect, following the approach of Buccella and Fanti (2016) in network industries which makes use of a game-theoretic approach, we show that in a Cournot framework, when the Government fixes an environmental standard in a polluting industry, i.e. upper limits to emissions, a high weight attached to the environment social concerns acts as a mechanism in favour of market entry. Nonetheless, if the size of the fixed costs for the entrant is adequately high, a welfare-damaging entry will occur: the duopoly market structure leads to a social welfare level lower than the monopoly. On the other hand, improvements in the efficiency of the abatement technology may work in the opposite direction of creating a barrier to entry when the government's social interest for controlling pollution is low.

The remainder of the paper is as follows. Section 2 presents the monopoly/duopoly model in the presence of environmental standards. Section 3 compares the outcomes under the monopoly/duopoly market structures and derives the key results. The welfare implications are also discussed. Section 4 brings the paper to its conclusions with some final remarks.

\section{The Model}

To analyse the market structure in which there is polluting production and pro-environment regulations (such as an upper limit on emissions), ${ }^{2}$ we follow the established literature, in particular the basic model of Copeland (1991) for a closed economy and adapted by Ulph (1996) for an open economy, ${ }^{3}$ and Barcena-Ruiz and Garzon (2001) for a mixed duopoly. Therefore, we assume that there are either one or two private firms (i.e. monopoly or duopoly) which produce homogeneous goods with the same polluting production technology. Moreover, 1) there is a public agency concerned with maintaining environmental quality, applying an environmental standard ${ }^{4}$ to control pollution; ${ }^{5}$ 2) each unit of the good produced causes one unit of pollutant; 3) the technology for abating this pollution is available to polluting firms, and is identical for each firm; 4) since each firm produces homogeneous goods with the same polluting technology, then the environmental standard is equal for all firms.

The producers have to abate pollution emissions to comply with the upper limit. This abatement entails a cost. If the government sets the environmental standard e and producer i chooses the output

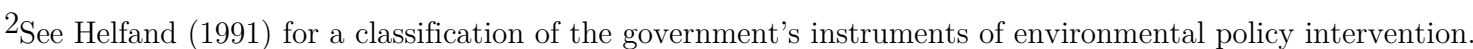

${ }^{3}$ On the issue of environmental standards in open economies, see also Ulph $(1992,1994)$.

${ }^{4}$ Alternatively, we could assume environmental taxes which are also increasingly implemented by public agencies (European Environment Agency, 2000). This is left for further research.

${ }^{5}$ For a taxonomy of the different forms of environmental standards see, for example, the Royal Commission on Environmental Pollution (RCEP) (1998), and Fanti (2015, Appendix). 
level $q_{i}$, producer i has to abate emissions by $\left(q_{i}-e\right)$. Thus, the total cost of pollution abatement $(C A)$ for firm $\mathrm{i}$ is assumed to be, as usual,

$$
C A_{i}=\kappa \frac{\left(q_{i}-e\right)^{2}}{2}, \quad \kappa>0, q \geq 0, e \geq 0, q \geq e
$$

where the parameter $\kappa$ scales up and down the total abatement cost and, thus, may be interpreted as a measure of the relative efficiency of the abatement technology. We assume that each firm has a constant marginal cost of production here normalized to zero for simplicity.

The timing of the game is the following. In the first stage, the government chooses the environmental standard. In the second stage, each firm chooses its output level. We solve the game by backward induction to obtain a subgame perfect Nash equilibrium.

\subsection{Monopoly}

As usual, the linear inverse demand function is

$$
p=a-q
$$

where $p$ denotes the price of the goods and $a$ is a demand parameter. It follows that the profit function of firm i is

$$
\pi_{i}=(a-q) q-\kappa \frac{(q-e)^{2}}{2}
$$

From the monopolist's profit maximisation, output is:

$$
q^{* M}=\frac{a+e \kappa}{2+\kappa}
$$

where the upper script " $M$ " stands for "monopoly".

\section{$2.2 \quad$ Government and Environment}

In line with the established literature (e.g. Falk and Mendelsohn, 1993; van der Ploeg and Zeeuw, 1992; Ulph, 1996; and Barcena-Ruiz and Garzon, 2006), we use a quadratic functional form to measure the environmental damage due to the monopoly's production activity. According to this type of damage function, the damage is exogenous for consumers and the environmental damage is a convex function of the total pollution level. ${ }^{6}$ The environmental damage $(E D)$ is given by:

$$
E D=\frac{\gamma}{2} e^{2}
$$

where the parameter $\gamma$ measures the government's valuation of the environment.

\subsection{Social Welfare and Environmental Standard}

Next, we solve the first stage of the game. In this stage the emission standard is chosen such that the social welfare, SW, is maximised. The social welfare considered by government comprises the consumer's surplus, CS, the monopolist's profits, $\pi^{M}$, and the environmental damage caused by the production process, ED. As usual, we assume the following social welfare function:

$$
S W=C S+\pi^{M}-E D
$$

where $C S=\frac{q^{2}}{2}$. The government fixes the following social welfare maximising environmental standard:

$$
\frac{\partial S W}{\partial e}=0 \Rightarrow e^{M}=\frac{a \kappa(3+\kappa)}{\mathrm{P}}
$$

where $\mathrm{P}=\gamma\left(\kappa^{2}+4 \kappa+4\right)+\kappa(\kappa+4)$. In the first stage equilibrium, quantity, profits and social welfare are given by, respectively:

6 Note that, since the emission abatement cost is a convex function (see eq. (1)), this class of models imply that the emission level of each firm is exactly the maximum permitted by the government, that is, the environmental standard $e$. 


$$
\begin{gathered}
q^{M}=\frac{a(\kappa+\gamma)(2+\kappa)}{\mathrm{P}} \\
\pi^{M}=\frac{a^{2}\left[\gamma^{2}(2+\kappa)^{3}+2 \gamma \kappa(2+\kappa)\left(\kappa^{2}+4 \kappa+4\right)+\kappa^{2}(3 \kappa+8)\right]}{(2 \mathrm{P})^{2}} \\
S W^{M}=\frac{a^{2}(\kappa+\gamma)(3+\kappa)}{2 \mathrm{P}}
\end{gathered}
$$

It is easy to see that $\frac{\partial q^{M}}{\partial e}>0, \frac{\partial q^{M}}{\partial k}<0$ : as is intuitive, the higher (lower) the level of the environmental standard (abatement cost parameter), the higher the output produced at equilibrium. Moreover, the constraint $q^{M} \geq e^{M}$ requires that at equilibrium

$$
\gamma \geq \frac{\kappa}{2+\kappa}
$$

\subsection{Duopoly}

The linear inverse demand function for the homogeneous goods is

$$
p=a-\left(q_{i}+q_{j}\right)
$$

The profit function of firm i is

$$
\pi_{i}=\left(a-q_{i}-q_{j}\right) q_{i}-\kappa \frac{\left(q_{i}-e\right)^{2}}{2}
$$

From profit maximisation by firm $i=\{1,2\}$, the marginal profits are obtained as:

$$
\begin{aligned}
& \frac{\partial \pi_{1}\left(q_{1}, q_{2}\right)}{\partial q_{1}}=a-2 q_{1}-\kappa q_{1}-q_{2}+e \kappa \\
& \frac{\partial \pi_{2}\left(q_{1}, q_{2}\right)}{\partial q_{2}}=a-2 q_{2}-\kappa q_{2}-q_{1}+e \kappa
\end{aligned}
$$

The reaction or best-reply functions of firms 1 and 2 are computed as the unique solution of eq. (14) and (15) for $q_{1}$ and $q_{2}$, respectively, and they are given by:

$$
\begin{aligned}
& \frac{\partial \pi_{1}\left(q_{1}, q_{2}\right)}{\partial q_{1}}=0 \Leftrightarrow q_{1}\left(q_{2}\right)=\frac{1}{2+k}\left(a+e k-q_{2}\right) \\
& \frac{\partial \pi_{2}\left(q_{1}, q_{2}\right)}{\partial q_{2}}=0 \Leftrightarrow q_{2}\left(q_{1}\right)=\frac{1}{2+k}\left(a+e k-q_{1}\right)
\end{aligned}
$$

Solving for (positive solutions of) $q_{1}$ and $q_{2}$, we get the optimal equilibrium values:

$$
q_{1}^{*}=q_{2}^{*}=q^{* D}=\frac{a+e k}{3+k}
$$

where the upper script " $D$ " stands for "duopoly". Also in the duopoly case it is easy to verify that

$$
\frac{\partial q^{* D}}{\partial e}>0, \frac{\partial q^{* D}}{\partial k}<0
$$

\subsection{Government, Social Welfare and Environmental Standards}

Next, we solve the first stage of the game. The social welfare considered by government comprises the consumer's surplus, CS, the sum of the firm profits in duopoly, $\pi^{D}$, and the environmental damage caused by the production process, ED. Also in the duopoly case the environmental standard is chosen such that the social welfare, SW, is maximised. The formal expression of the social welfare function in duopoly is: 
where

$$
S W=C S+2 \pi^{D}-E D
$$

$$
C S=\frac{\left(q_{1}+q_{2}\right)^{2}}{2} \text { and } E D=\frac{\gamma}{2}(2 e)^{2}
$$

The government fixes the following social welfare maximising environmental standard:

$$
\frac{\partial S W}{\partial e}=0 \Rightarrow e^{D}=\frac{a \kappa(4+\kappa)}{\Psi}
$$

where $\Psi=2 \gamma\left(\kappa^{2}+6 \kappa+9\right)+\kappa(2 \kappa+9)$. In the first stage equilibrium, quantity, profits and social welfare are given by, respectively:

$$
\begin{gathered}
q^{D}=\frac{a(\kappa+3)(2 \gamma+\kappa)}{\Psi} \\
\pi^{D}=\frac{a^{2}\left[4 \gamma^{2}(\kappa+2)(3+\kappa)^{2}+4 \gamma \kappa(3+\kappa)\left(\kappa^{2}+5 \kappa+6\right)+\kappa^{2}(5 \kappa+18)\right]}{2 \Psi^{2}} \\
S W^{D}=\frac{a^{2}(\kappa+2 \gamma)(4+\kappa)}{\Psi}
\end{gathered}
$$

In the duopoly case the constraint $q^{D} \geq e^{D}$ requires that at equilibrium $\gamma \geq \frac{\kappa}{2(3+\kappa)}$. It is easy to see that the condition (11) is the most stringent. It is assumed and verified that this holds for the rest, such that all the results herein satisfy such a constraint.

\section{Comparisons and Market Structure}

From the analysis of (7) and (21) and their direct comparison, we observe that 1) standards are decreasing with increasing $\gamma$ and decreasing $\kappa$, in accord with the intuition; and 2) they are always larger under monopoly than duopoly. This means that the monopolist in principle should pay less than duopolistic firms for abating pollution. However, the standards differential between monopoly and duopoly, although always positive, is variable according to a nontrivial interaction between the levels of $\gamma$ and $\kappa$. Therefore, these various effects on the standards differentials are a main reason why $\gamma$ and especially $\kappa$ may play not univocal roles on the possibility of entry, as below shown. Suppose that the monopolist has to pay cost $L$ to establish a barrier to entry, such as a license fee to be paid to the government or lobby expenditures. Let us define the following profits differential:

$$
\Delta \pi=\pi^{M}-L-\pi^{D}=\frac{a^{2}\left[\begin{array}{l}
\left(4 \gamma^{4}(2+\kappa)\left(2 \kappa^{5}+25 \kappa^{4}+124 \kappa^{3}+305 \kappa^{2}+372 \kappa+180\right)+\right. \\
4 \gamma^{3}\left(\kappa^{7}+168 \kappa^{5}+770 \kappa^{4}+2083 \kappa^{3}+3330 \kappa^{2}+2916 \kappa+1080\right)+ \\
\gamma^{2} \kappa^{2}\left(8 \kappa^{6}+143 \kappa^{5}+1060 \kappa^{4}+4061 \kappa^{3}+8734 \kappa^{2}+9928 \kappa+4680\right)+ \\
2 \gamma \kappa^{3}\left(2 \kappa^{5}+35 \kappa^{4}+243 \kappa^{3}+846 \kappa^{2}+1498 \kappa+1080\right)+\kappa^{4}+ \\
\left(7 \kappa^{3}+82 \kappa^{2}+307 \kappa+360\right)
\end{array}\right]}{2(\mathrm{P \Psi})^{2}}-L
$$

Eq. (25) is not algebraically tractable; therefore, we resort to the graphical analysis to obtain clear-cut results as regards the role the two crucial parameters $\gamma$ and $\kappa$ play on entry. In the next, to simplify the analysis, we consider that $L=0:$ a value of $L>0$ simply magnifies the effects of our results.

Result 1. The higher the government's valuation of the environment is, the better the entry of a firm is facilitated (see Fig. 1 and Appendix).

Result 1 has a so far not explored consequence: an environmental policy involuntarily implies that the incumbent is forced to face a more competitive market structure. Thus, ultimately, the environmental policy acts as a competition policy. 


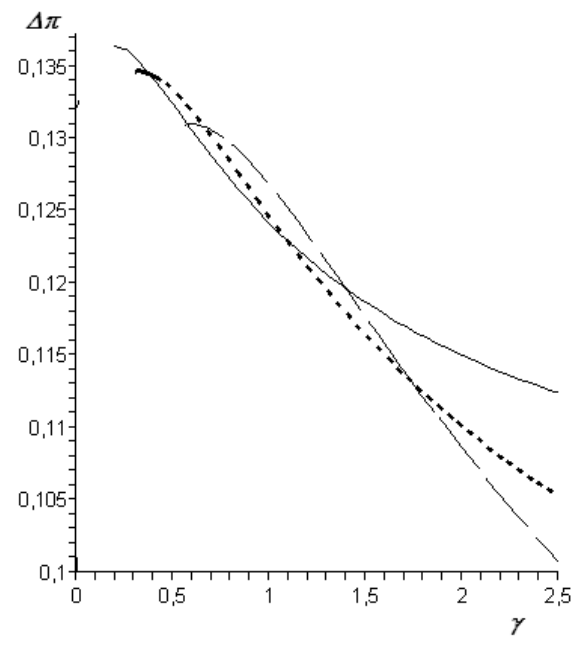

Figure 1. Plot of the profit differential $\Delta \pi$ with an increasing damage's social evaluation $(\gamma)$ for three different technological cost parameter $(\kappa)$. Legend: $\kappa=0.5$ (solid line), $\kappa=1$ (dotted line), $\kappa=3$ (long-dashed line).

Result 2. The role played by the technological abatement cost parameter on entry of a firm is ambiguous, depending on the values of the valuation of the environment by the government: i) when the latter is low (i.e. $\gamma<1$ ) an initial increase of the cost parameter starting from zero "favours" entry until $\kappa=\kappa^{\circ}$. However, for further increases up to a threshold value of $\kappa=\kappa^{\circ}$, the cost parameter disfavours entry. Finally, increases beyond $\kappa^{\circ o}$ switch to favour entry again; ii) for values of the valuation of the environment neither too low nor too high (namely $1<\gamma<3.5$ ), an initial increase of the cost parameter starting from zero "favours" entry until a threshold value of $\kappa=\kappa^{\circ}$ is reached; however, further increases always tend to disfavour entry; iii) values of the valuation of the environment sufficiently high (i.e. $\gamma>3.5$ ) always favour entry (see Fig. 2).

Lemma 1. Social welfare under both monopoly and duopoly, as intuitively expected, is always decreasing with an increasing valuation of the environment as well as abatement cost parameter. ${ }^{7}$

These results mean that while, on the one hand, the valuation of the environment always reduces welfare, on the other hand favours the entry of a firm and, thus, a more competitive market structure. By contrast, a more efficient abatement technology, while obviously always enhances welfare, also works either as a barrier to entry or as an incentive to entry of a firm depending on whether the evaluation of environment by government is low or high, respectively. In other words, if the government highly evaluates environment, the monopolist has an incentive to innovate the abatement technology which is working as a barrier to entry; however, by contrast, if the social evaluation of environment is low the monopolist could not innovate and it may even worsen the abatement technology to disfavour entry.

These findings offer clear-cut empirical implications: less (more) competitive market structures should be more often identified where environmental concerns are scarcely (strongly) present and abatement technologies are relatively inefficient (efficient). Moreover, interesting policy implications are that incentives for enhancing productivity of the abatement plants may act as a barrier to entry and, on the whole, be potentially harmful for welfare. Conversely, to be very careful about environment, although directly reduces welfare, may be indirectly welfare-enhancing by allowing entry of a firm.

\footnotetext{
${ }^{7}$ The proof straightforwardly follows from the derivative of (10) and (24), respectively, with respect to $\gamma$ and $\kappa$; the expressions are here omitted for economy of space.
} 


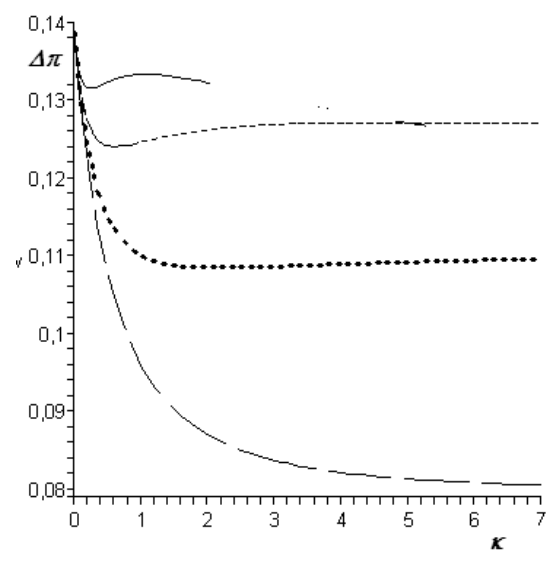

Figure 2. Plot of the profit differential $\Delta \pi$ with an increasing technological cost parameter $(\kappa)$ for four different values of the damage's social evaluation $(\gamma)$. Legend: $\gamma=0.5$ (solid line) $8, \gamma=1$ (short-dashed line), $\gamma=2$ (dotted line), $\gamma=4$ (long-dashed line).

As a simple but illustrative example, let us consider the following cases. First, suppose that the government's valuation of the environment is $\gamma=1$, such that condition (11) is satisfied $\forall \kappa>0$. Consider also, without loss of generality, that the parameter $a=1$. Moreover, suppose that the entrant faces some fixed costs $F$. At $\gamma=1$, from eq. (9), it is easily observed that if $F_{T}^{M}>\frac{\kappa^{4}+8 \kappa^{3}+19 \kappa^{2}+14 \kappa+4}{4\left(\kappa^{2}+4 \kappa+2\right)^{2}}$ (where T stands threshold), no firms are active in the market because $\pi^{M}<0$. From eq. (23), it is derived that if $F_{T}^{D}>\frac{4 \kappa^{4}+41 \kappa^{3}+134 \kappa^{2}+156 \kappa+72}{2\left(4 \kappa^{2}+21 \kappa+18\right)^{2}}$, only the monopolist operates in the market because $\pi^{D}<0$. Thus, for $F \in\left[F_{T}^{D}, F_{T}^{M}\right]$, monopoly is the industry market structure.

Given eq. (10) and (24), for $\gamma=1$ the social welfare differential between monopoly and duopoly $\Delta S W=S W^{M}-\left(S W^{D}-F\right) \geq 0$ leads to $F^{*} \geq \frac{3 \kappa^{3}+22 \kappa^{2}+41 \kappa+10}{4\left(\kappa^{2}+4 \kappa+2\right)\left(4 \kappa^{2}+21 \kappa+18\right)}$. It can be easily checked that $F^{*}<F_{T}^{D}$, as also depicted in Fig.3, left box.

In other words, if $F \in\left[F^{*}, F_{T}^{D}\right)$, duopoly is the market structure, however the social welfare under monopoly is higher than the social welfare under duopoly. On the other hand, for $F \in\left[0, F^{*}\right)$, duopoly is the market structure and leads also to the superior welfare outcome. Fig.3, right box, graphically reports the results of the analogous exercise for the value of $\gamma=5$, from which it immediately appears the procompetitive and welfare enhancing effect of the government's environmental valuation especially in the presence of efficient abatement technologies.

Second, let us reverse the analysis and explore the impact on welfare of different degrees of environmental sensitivity for given levels of the abatement technology's efficiency. Suppose that the abatement efficiency parameter is $\kappa=1$ : condition (11) leads to consider a value of $\gamma \geq \frac{1}{3}$.

Consider again, without loss of generality, that $a=1$. The entrant always faces the fixed costs $F$. At $\kappa=1$, from eq. (9), it can be easily checked that if

\footnotetext{
${ }^{8}$ Note that the curve is truncated beyond $\kappa>2$ because condition (11) would be violated.
} 

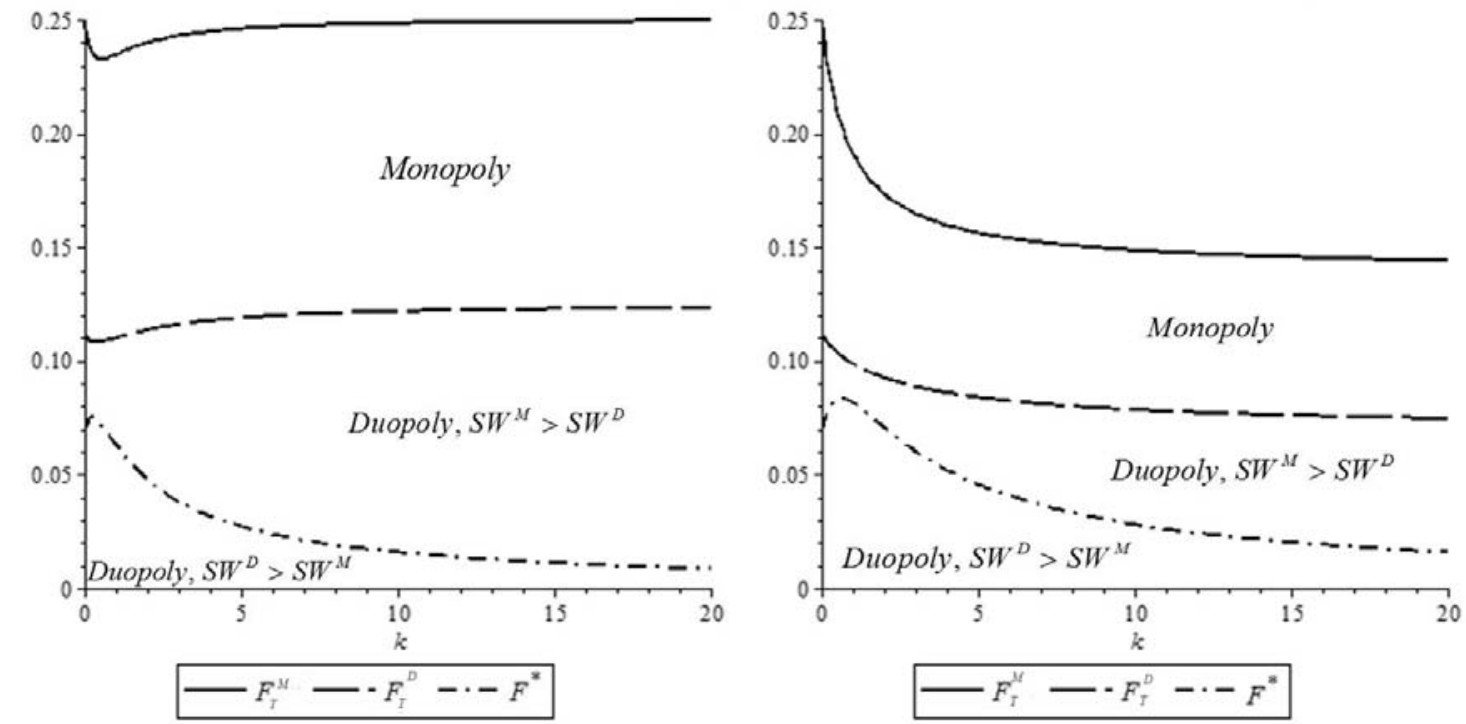

Figure 3. Plot of the relation between market structures and welfare levels for two different values of the damage's social evaluation $(\gamma)$, in the presence of entry costs and with an increasing technological cost parameter $(\kappa)$. Left box: $\gamma=1$; right box $\gamma=5$.
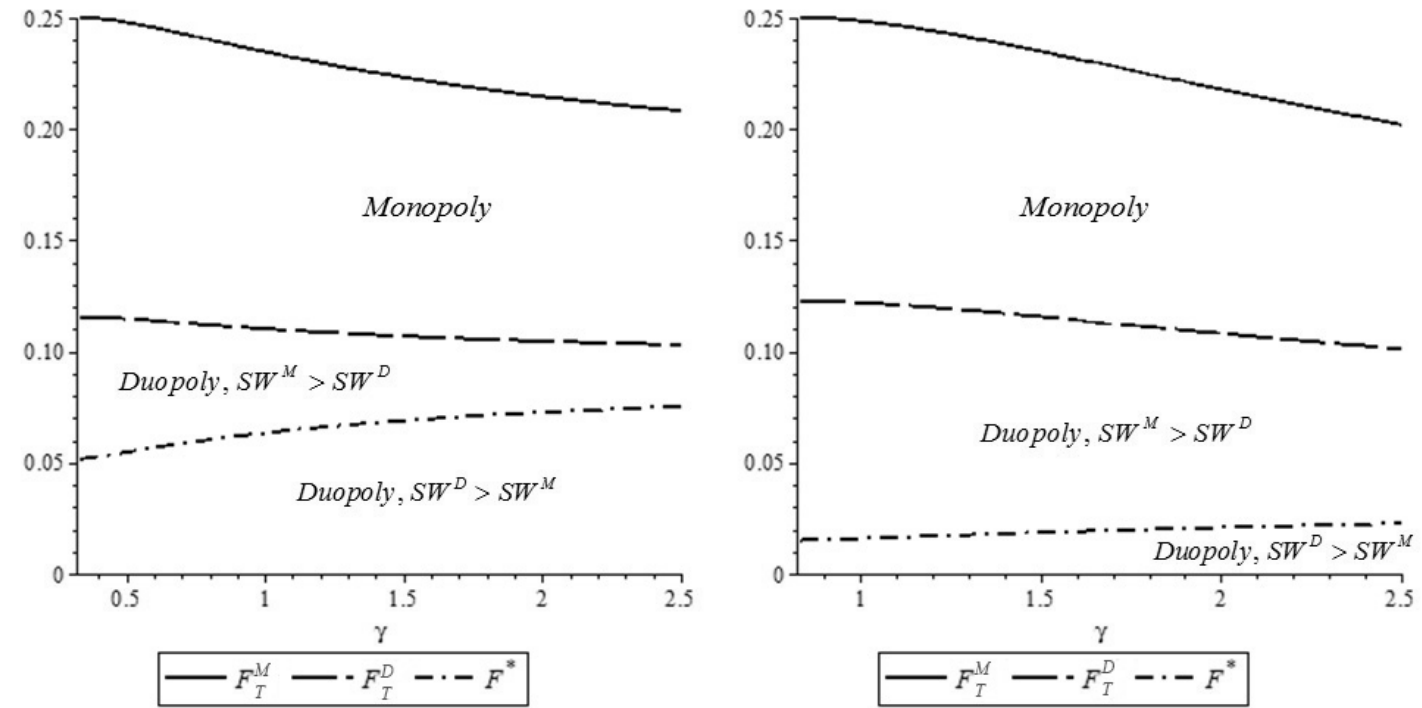

Figure 4. Plot of the relation between market structures and welfare levels for two different values of the technological cost parameter the $(\kappa)$, in the presence of entry costs and with an increasing damage's social evaluation $(\gamma)$. Left box: $\kappa=1$; right box $\kappa=10$.

$F_{T}^{M}>\frac{27 \gamma^{2}+54 \gamma+11}{2(9 \gamma+5)^{2}}$ no firms operate in the market because $\pi^{M}<0$. From eq. (23), it is also derived that if $F_{T}^{D}>\frac{192\left(\gamma^{2}+\gamma\right)+23}{2(32 \gamma+11)^{2}}$, only the monopolist is active because $\pi^{D}<0$. Thus, for $F \in\left[F_{T}^{D}, F_{T}^{M}\right]$, the industry market structure is a monopoly. 
As before, from eq. (10) and (24) it can be found that, for $\kappa=1$ the social welfare differential between monopoly and duopoly $\Delta S W=S W^{M}-\left(S W^{D}-F\right) \geq 0$ yields $F^{*} \geq \frac{26 \gamma^{2}+9 \gamma+3}{(9 \gamma+5)(32 \gamma+11)}$, with $F^{*}<F_{T}^{D}$ as Fig.4 left box shows. As in the previous case, if $F \in\left[F^{*}, F_{T}^{D}\right)$, duopoly is the industry structure but social welfare under monopoly is higher than under duopoly. On the other hand, for $F \in\left[0, F^{*}\right)$, the duopoly industry yields also to the superior welfare outcome. Fig.4, right box, reports the results of the analogous exercise for $\kappa=10$. A graphical inspection confirms that 1) for a given level of efficiency of the abatement technology, the government's low (high) evaluation of the environment works as a barrier (incentive) to entry; and 2) a more efficient abatement technology tends to disfavour entry (it increases the threshold value of $F_{T}^{D}$ ).

\section{Concluding Remarks}

Making use of a Cournot framework, this paper has investigated the impact of public environmental policies on the market structure in a polluting industry. The work has shown that, when the Government sets upper limits to emissions, higher environmental social concerns act in favour of market entry for a firm. Moreover, besides the pro-competitive effect, the government's environmental social concern has welfare enhancing effects, especially in the presence of efficient abatement technologies. In other words, this paper highlights that a high government's environmental sensitivity has an involuntary effect of favouring competition and, de facto, operates as a competition policy. On the other hand, an enhancement of the abatement technology's efficiency may play the role of a barrier to entry when the social interest for controlling pollution is low; in addition, the adoption of a more efficient technology may disfavour entry.

Nonetheless, if the burden of the fixed costs the entrant has bear is relatively but not prohibitively high, market entry takes place and duopoly is the industry structure; however, the social welfare under monopoly is higher than under duopoly. The consequences in terms of policy are evident. There is a trade-off between the environmental and competition policy: the former tries to improve the market structure, the latter may result in a social damage.

Further research could and should be devoted to checking the robustness of these results to different: i) instruments of environmental policy such as emission taxes ${ }^{9}$ and emission permits; ii) modes of competition (e.g. Bertrand); iii) contexts such as international competition and unionised labour markets; iv) behavioural rules of firms, such as managerial delegation of firm's choices by firm's owners and corporate social responsibility.

\section{References}

1. J.C. Bárcena Ruiz, and M. B. Garzón San Felipe, "Mixed Oligopoly and Environmental Policy", Spanish Economic Review, vol. 8, no. 2, pp. 139-160, 2006.

2. A.H. Barnett, "The Pigouvian Tax Rule under Monopoly", The American Economic Review, vol. 70, pp. 1037 1041, 1980.

3. W.J. Baumol, and E.N. Oates, The Theory of Environmental Policy. Cambridge: Cambridge University Press, 1988.

4. D. Besanko, "Performance Standards versus Design Standards in the Regulation of Pollution", Journal of Public Economics, vol. 34, pp. 19-44, 1987.

5. D. Buccella, and L. Fanti, "Entry in a Network Industry with a "Capacity-Then-Production" Choice", Seoul Journal of Economics, vol. 29, no. 3, pp. 411-429, 2016.

6. J. Church, and R. Ware, Industrial Organization: A Strategic Approach. Boston, MA: Irwin McGraw-Hill, 1999.

${ }^{9}$ Preliminary results of our research in progress reveal that the present findings also extend qualitatively to the case of emission taxes (instead of environmental standards), although in such a case also new findings on the effects of post-entry social welfare emerge. 
7. B. Copeland, "Taxes versus Standards to Control Pollution in Imperfectly Competitive Markets", mimeo, University of British Columbia, 1991.

8. A. Dixit, "The role of investment in entry-deterrence", The Economic Journal, vol. 90, no. 357, pp. 95-106, 1980.

9. U. Ebert, "Pigouvian Taxes and Market Structure: The Case of Oligopoly and Different Abatement Technologies", Finanzarchiv, vol. 49, pp. 154-166, 1992.

10.European Environment Agency, Environmental taxes: recent developments in tools for integration. Environmental Issues Series, No. 18, 2000.

11.I. Falk, and R. Mendelson, "The economics of controlling stock pollutants: An efficient strategy for greenhouse gases", Journal of Environmental Economics and Management, vol. 25, pp. 75-88, 1993.

12.L. Fanti, "Environmental Standards and Cournot Duopoly: A Stability Analysis", Environmental and Resource Economics, vol. 61, no. 4, pp. 577-593, 2015.

13.G. Helfand, "Standards versus Standards: The Effects of Different Pollution Restrictions", The American Economic Review, vol. 81, no. 3, pp. 622-634, 1991.

14.R. Innes, C. Kling, and J. Rubin, "Emission Permits under Monopoly", Natural Resource Modelling, vol. 8, pp. 321-343, 1991.

15.R.S. Khemani, and D.M. Shapiro, "Glossary of Industrial Organisation Economics and Competition Law". Directorate for Financial, Fiscal and Enterprise Affairs, OECD, 1993.

16.D. Levin, "Taxation within Cournot Oligopoly", Journal of Public Economics, vol. 27, pp. 281—290, 1985.

17.R.P. McAfee, H.M. Mialon, and M.A. Williams, "What is barrier to entry?", The American Economic Review, vol. 94, no. 2, pp. 461-465, 2004.

18.W.E. Oates, and D.L. Strassmann, "Effluent Fees and Market Structure", Journal of Public Economics, vol. 24, pp. 29-46, 1984.

19.T. Requate, "Equivalence of Effluent Taxes and Permits for Environmental Regulation of Several Local Monopolies", Economics Letters, vol. 42, pp. 91—95, 1993.

20.T. Requate, Environmental policy under imperfect competition. In: Tietenberg, T., Folmer, H. (Eds.), The International Yearbook of Environmental and Resource Economics 2006/2007. A Survey of Current Issues. Edward Elgar, 2006.

21.Royal Commission on Environmental Pollution (RCEP), Environmental Standards and Public Values. A Summary of the Twenty-first Report of the Royal Commission on Environmental Pollution. The Stationery Office, London, 1998.

22.O. Shy, Industrial Organization: Theory and Application. MIT Press, Cambridge, MA, 1995.

23.D. Simpson, "Optimal Pollution Taxation in a Cournot Duopoly", Environmental and Resource Economics, vol. 6, pp. 359-369, 1995.

24.A.M. Spence, "Entry, capacity, investment and oligopolistic pricing", The Bell Journal of Economics, vol. 8, no. 2, pp. 534-544, 1977.

25.D.F. Spulber, "Effluent Regulation and Long-run Optimality", Journal of Environmental Economics and Management, vol. 12, pp. 103-116, 1985.

26.J.E. Stiglitz, Introduction. In New Developments in the Theory of Market Structure. J. E. Stiglitz and F. Mathewson (eds.). The MIT Press. Cambridge, Massachusetts, 1986.

27.A. Ulph, "The Choice of Environmental Policy Instruments and Strategic International Trade". In Conflict and Cooperation in Managing Environmental Resources. R. Pethig (ed.). Springer-Verlag, Berlin, 1992.

28.A. Ulph, "Environmental Policy and International Trade: A Survey of Recent Economic Analysis", Nota di Lavoro, vol. 53.94., 1994.

29.A. Ulph, "Environmental policy and international trade when governments and producers act strategically", Journal of Environmental Economics Management, vol. 30, pp. 256-281, 1996.

30.F. van der Ploeg, and A.J. de Zeeuw, "International aspects of pollution control", Environmental and Resource Economics, vol. 2, pp. 117-139, 1992. 


\section{Appendix}

We provide some analytical insights about Result 1 and figure 1 . We fix $\kappa=1$ in order to have a profit differential algebraically tractable. In this case

$$
\left.\frac{\partial \Delta \pi}{\partial \gamma}\right|_{\kappa=1}=-\frac{4\left(709776 \gamma^{4}+384192 \gamma^{3}-55296 \gamma^{2}-44607 \gamma-1979\right)}{(32 \gamma+11)^{3}(9 \gamma+5)^{3}} .
$$

It is easily verified that $\left.\frac{\partial \Delta \pi}{\partial \gamma}\right|_{\kappa=1} \geq 0 \Leftrightarrow \gamma \frac{<}{>} \frac{1}{3}$. Therefore, since condition (11) requires that $\gamma \geq \frac{1}{3}$, the profit differential is always decreasing with an increasing $\gamma$. Note that the above demonstration qualitatively holds for whatever value of $\kappa$, as the reader can easily see by substituting any values of $\kappa$ in (25). 